\title{
The cyclic AMP signaling pathway: Exploring targets for successful drug discovery (Review)
}

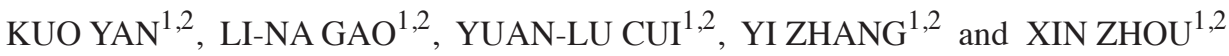 \\ ${ }^{1}$ Research Center of Traditional Chinese Medicine; ${ }^{2}$ Tianjin State Key Laboratory of Modern Chinese Medicine, \\ Tianjin University of Traditional Chinese Medicine, Tianjin 300193, P.R. China
}

Received April 6, 2015; Accepted February 8, 2016

DOI: $10.3892 / \mathrm{mmr} .2016 .5005$

\begin{abstract}
During development of disease, complex intracellular signaling pathways regulate an intricate series of events, including resistance to external toxins, the secretion of cytokines and the production of pathological phenomena. Adenosine 3',5'-cyclic monophosphate (cAMP) is a nucleotide that acts as a key second messenger in numerous signal transduction pathways. cAMP regulates various cellular functions, including cell growth and differentiation, gene transcription and protein expression. This review aimed to provide an understanding of the effects of the cAMP signaling pathway and the associated factors on disease occurrence and development by examining the information from a new perspective. These novel insights aimed to promote the development of novel therapeutic approaches and aid in the development of new drugs.
\end{abstract}

\section{Contents}

1. Introduction

2. Indicators involved in the cAMP signaling pathway and their detection methods

3. Inhibitors and activators involved in cAMP signaling pathway-associated diseases

4. Cross-talk of the cAMP signaling pathway with other pathways

5. Future directions

Correspondence to: Professor Yuan-Lu Cui, Research Center of Traditional Chinese Medicine, Tianjin University of Traditional Chinese Medicine, 88 Yuquan Road, Nankai District, Tianjin 300193, P.R. China

E-mail: cuiyl@tju.edu.cn

Key words: cyclic adenosine monophosphate, detection method, inhibitor, activator, drug discovery

\section{Introduction}

Substances that convert extracellular signals received by cell surface receptors to intracellular signals are known as second messengers (Fig. 1). Extracellular chemical substances (first messengers) cannot enter cells directly, however translate physical and chemical signals into adenosine 3',5'-cyclic monophosphate (cAMP) and cyclic guanosine monophosphate (cGMP) within the cells via cell surface receptors. Intracellular second messengers include cAMP, cGMP, nucleotides, lipids and other small molecules (1). The recognition process between intracellular second messengers and extracellular receptors gives rise to a series of biochemical reactions that result in several physiological effects.

Second messengers convert and amplify extracellular signals by activating protein kinases that serve physiological roles or by acting on intracellular ligand-gated channels to alter the membrane potential. The degradation of these second messengers leads to signal termination. It has been identified that numerous signaling pathways are triggered by second messengers including cAMP, diacylglycerol, inositol triphosphate ( $\left.\mathrm{IP}_{3}\right)$, cGMP and $\mathrm{Ca}^{2+}$. This review focuses primarily on reviewing cAMP, an important second messenger, and the associated cell signal transduction pathway. Signal response factors associated with cAMP are discussed below and the current understanding of the cAMP signaling pathway is presented in Fig. 1.

Adenylate cyclase (AC) converts adenosine triphosphate (ATP) into cAMP, which stimulates cAMP-dependent protein kinase A (PKA). Subsequently, specific proteins are phosphorylated by PKA (2) to evoke cellular reactions. The phosphorylation of the cAMP response-element binding-protein (CREB), a transcription factor, is important in the regulation of gene transcription (3). Extracellular signals activate the transcription of a variety of target genes via alterations in CREB phosphorylation, thereby, resulting in multiple physiological functions (4). Phosphodiesterases (PDEs) are an enzyme superfamily that have been demonstrated to catalyze the hydrolysis of intracellular second messenger molecules, including cAMP and cGMP; therefore, the inactivation of PDE will indirectly increase the level of cAMP in cells (5).

Second messenger pathways are associated with numerous conditions and diseases, including inflammation $(6,7)$, cancer $(8,9)$, myocardial atrophy (2), asynodia (10) and depression (11). All of the conditions and diseases mentioned above 

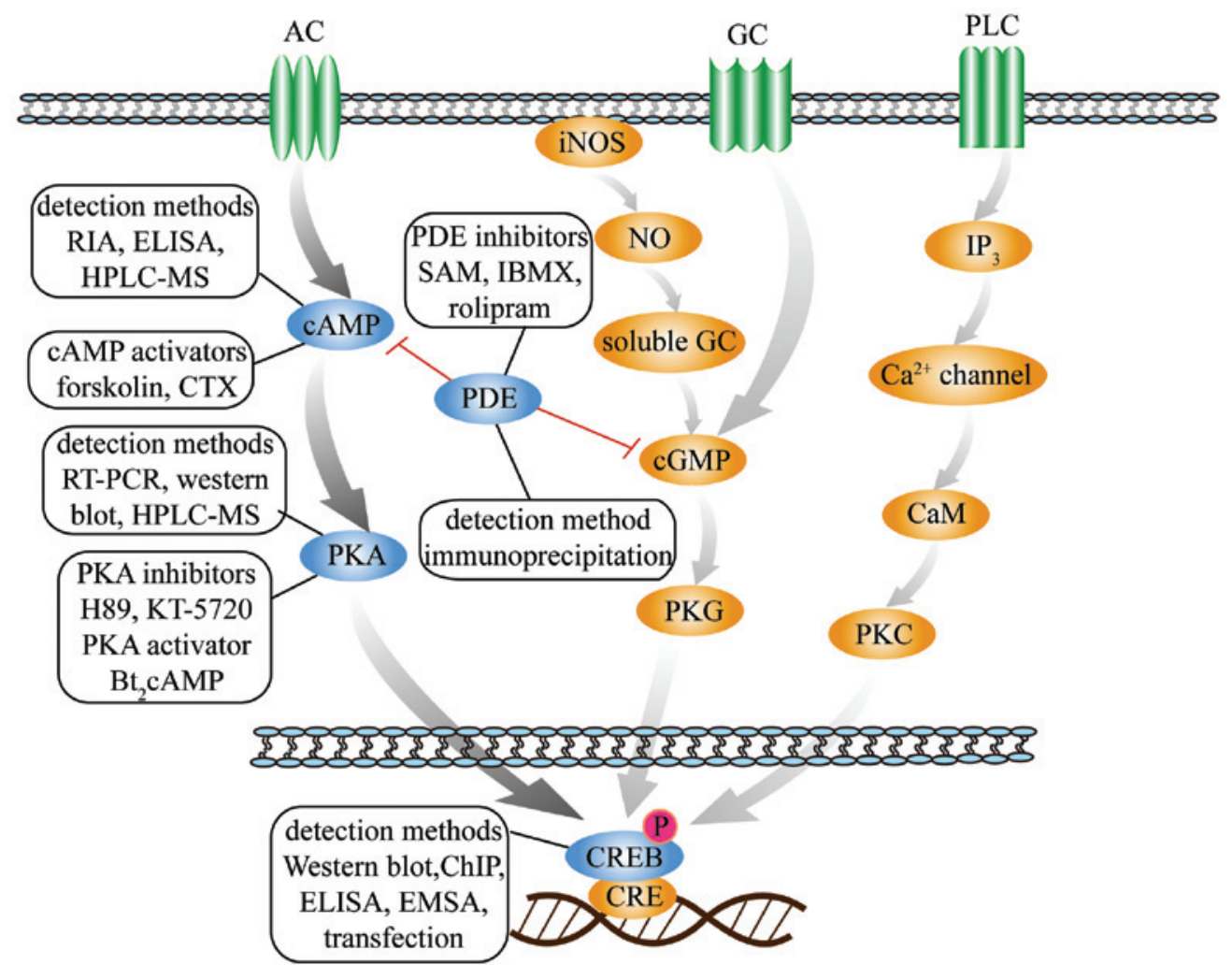

Figure 1. Schematic diagram of second messenger signaling pathways. The figure presents three second messengers involved in three signal transduction pathways, including cAMP-PKA-CREB, NO-cGMP-PKG and IP3-Ca ${ }^{2+}-\mathrm{PKC}$. The detection methods, inhibitors and activators of cAMP, PKA, PDE and CREB in the cAMP-PKA-CREB pathway are depicted. cAMP, adenosine 3',5'-cyclic monophosphate; PKA, protein kinase A; CRE, cAMP response-element; CREB, CRE binding-protein; NO, nitric oxide; cGMP, cyclic guanosine monophosphate; PKG, protein kinase G; IP3, inositol triphosphate; PKC, protein kinase C; PDE, phosphodiesterase; iNOS, inducible nitric oxide synthase; AC, adenylate cyclase; GC, guanylyl cyclase; PLC, phospholipase C; CaM, calmodulin RIA, radioimmunoassay; ELISA, enzyme-linked immunosorbent assay; HPLC-MS, high performance liquid chromatography-mass spectrometry; CTX, cholera toxin; RT-PCR, reverse transcription-quantitative polymerase chain reaction; ChIP, chromatin immunoprecipitation; EMSA, electrophoretic mobility shift assay; SAM, S-adenosylmethionine; IBMX, 3-isobutyl-1-methylxanthine.

involve the cAMP signaling pathway and its branch pathway. Due to the importance and varied functions of the cAMP signaling pathway, Gloerich and Bos (12) and Nakajima et al (13) studied the underlying mechanisms in detail. The present review discusses the methods used to detect the cAMP signaling pathway, as well as the diseases associated with the pathway.

\section{Indicators involved in the CAMP signaling pathway and their detection methods}

cAMP is synthesized from ATP via the action of AC and is inactivated by hydrolysis to AMP by PDE (14). As a result of the degradation of cAMP by PDE, the catalytic portion of PKA is effectively prevented from translocating to the nucleus and generating phosphorylated-CREB (p-CREB) (15). cAMP regulates numerous cellular functions, including metabolism, transcription and growth, in the majority of cell types. These cAMP effects, mediated primarily by cAMP-dependent PKA, are at the root of CAMP-mediated regulation of various physiological processes, including endocrine, cardiovascular, neuronal and immune functions (16-18). Research on cAMP signaling pathways requires the detection of the signaling system at various levels, including each target factor.

Methods to detect $c A M P$. cAMP, as an important messenger involved in the regulation of metabolism and biological functions in cells, transfers information regarding cellular status. With functions including the regulation of neurotransmitter synthesis (19), regulation of membrane protein activity, participation in ganglion synaptic transmission (20) and regulation of transcription factors in eukaryotic cells (21), cAMP may be involved in the prevention and treatment of various diseases. Therefore, detecting the level of cAMP is important in the investigation of medically relevant signal transduction pathways.

An immunochemical assay is a fast and effective method for detecting cAMP in the field of biomedical research. Developed in the 1970's, a radioimmunoassay (RIA) (22) is used to detect the concentration of cAMP. An RIA is a radionuclide-labeled immune analysis method. The basic principle of an RIA is a competitive binding reaction between a radioisotope-labeled antigen and an unlabeled antigen for a specific antibody. An RIA is a method that employs a competitive inhibition reaction and is characterized by high sensitivity, strong specificity and low cost. An RIA is convenient for the early detection of biological samples, however there are concerns with this assay regarding experimental safety and environmental protection.

Due to safety considerations, the subsequently developed enzyme-linked immunosorbent assay (ELISA) has greater advantages than an RIA. This method is based on an immunocompetitive binding technique. Currently available ELISA kits that measure cAMP levels are based on non-affinity-purified 
polyclonal anti-cAMP antibodies. Numerous studies have reported on the use of commercially available ELISA kits for the determination of cAMP $(23,24)$. This method depends on specific adsorption and the combination of the antibody and antigen. The cAMP in the sample or standard competes with a horseradish peroxidase (HRP)-labeled cAMP conjugate for binding sites on the anti-cAMP antibodies, and the results are measured with a multifunctional microplate reader to calculate the antibody or antigen concentration. To improve the detection sensitivity, numerous commercial kits suggest pretreating the samples using acetylation. The substrate system for the ELISA method typically utilizes the reaction of HRP with tetramethylbenzidine (24). To improve the stability of this detection method, the Ellman reagent system from Cayman Chemical Company (Ann Arbor, MI, USA) is helpful. Fluorescent and chemiluminescent substrates (25), which are able to greatly improve the sensitivity of detection, were subsequently developed.

The LANCE-cAMP assay, which was developed by PerkinElmer Life and Analytical Sciences, Inc. (Shelton, CT, USA) and is another alternative approach for determining cAMP levels (26), is a homogeneous time-resolved fluorescence resonance energy transfer method. Initially, cell treatment is conducted, after which the samples are diluted and the intracellular cAMP level is determined using the LANCE-cAMP kit. The samples are appropriately prepared for time-resolved fluorescence measurements according to the manufacturer's instructions. Additionally, there are several other detection technologies, such as the scintillation proximity assay (27) and the high performance liquid chromatography-mass spectrometry (HPLC-MS) analysis technique.

Methods to detect PKA. By catalyzing phosphorylation in response to hormonal stimulation, PKA is the primary mediator of cAMP function and a key regulatory enzyme in pivotal cellular processes, such as DNA replication $(28,29)$, cell growth and metabolism (30), cell division and rearrangement of the actin cytoskeleton $(31,32)$. Due to the fact that PKA is a type of protein kinase, the methods used in PKA research are divided into three groups: The detection of kinase activity, mRNA expression levels and protein expression levels.

Commonly used PKA detection methods include reverse transcription-polymerase chain reaction (RT-PCR), western blot analysis and non-radioactive assays. Yang et al (33) obtained the cDNA of rat hepatic stellate cells by reverse transcription, then used forward (5'-GCTGGCTTTGATTTA CGG-3') and reverse (5'-GATGTTTCGCTTGAGGATA-3') primers for the target gene (505 bp). The RT-PCR products were then separated by agarose gel electrophoresis, and the results analyzed with a gel image-analysis system.

Western blot analysis is used to detect the expression of PKA proteins. In western blot analysis, polyacrylamide gel electrophoresis (PAGE) is used to separate proteins, and immunochemical staining or autoradiography is then used to detect the electrophoretically separated protein expressed by a specific gene. In general, this method is used to detect p-PKA with p-(Ser/Thr) PKA-specific antibodies (34-37).

Commercially available kits for the rapid detection of protein kinases have been used for many years. According to the characteristics of a phosphate kinase, detection technology was developed utilizing radioactive phosphorus $32\left({ }^{32} \mathrm{P}\right)$ as a marker. Although this method is effective, the large quantity of ${ }^{32} \mathrm{P}$ used makes this assay inconvenient and potentially hazardous. However, a non-radioactive protein kinase assay (38) for PKA is now available. This system is based on the high affinity binding of biotin to streptavidin. In addition, a fluorescent peptide substrate is used. This method was designed to be rapid, sensitive and safe.

Due to experimental safety and environmental protection considerations, researchers have been trying to develop increased numbers of non-radioactive detection technologies to detect the activity of PKA. HPLC-MS, which uses liquid chromatography as the separation system and mass spectrometry as the detection system, has been suggested to be effective for measuring PKA activity. Samples are separated by mass in a packed column under high-pressure flow. The samples are then ionized, and the mass analyzer separates the ion fragments in accordance with mass number. The mass spectra are created by the detector. Fujikawa et al (39) and Kanno et al (40) used a reversed-phase HPLC system in which phosphorylated and non-phosphorylated peptides were detected at an absorbance of $214 \mathrm{~nm}$. The areas of the non-phosphorylated and phosphorylated substrate peptides (pmol/min) were used as the index of PKA activity. This method combined the high separation capability of chromatography with the high selectivity and high sensitivity of mass spectrometry; therefore, HPLC-MS has the advantages of rapid analysis and amenability to automation.

Methods to detect CREB. CREB is a nuclear transcription factor. Non-phosphorylated CREB is predominantly located in the nucleus. PKA that is activated by cAMP translocates to the nucleus and activates CREB through the phosphorylation of the amino terminal kinase inducible domain, in turn regulating target gene transcription (41-43). CREB is divided into the $\mathrm{C}$-terminal and $\mathrm{N}$-terminal domains. The $\mathrm{N}$-terminus is the transcription activation site, which contains multiple phosphorylation sites, including serine residue 133 (Ser133), Ser142 and Ser143, which can be phosphorylated by a variety of protein kinases. Ser133 serves an important role in the transcriptional activity of CREB (44-47). The phosphorylation of these sites is associated with downstream protein expression and function. Therefore, the detection of these phosphorylated sites is crucial to the study of signal transduction pathways.

$A$ variety of methods have been developed to detect CREB. The most widely used is western blot analysis and transfection together with the luciferase assay. In western blotting method, the protein samples are separated by PAGE; the proteins are then transferred to membranes and subsequently probed with a specific antibody. The antibodies most commonly used for the above purpose are against CREB (total) (26), p-CREB (Ser133) $(26,48)$ and p-CREB (Ser129) (49).

Due to the importance of CREB and its phosphorylation, it has become a focus in research for targets of novel drug research and development. The ELISA method, which is suitable for high throughput screening, is well established and is widely used in drug discovery. Therefore, the cell-based ELISA method based on the double fluorescent labeling technique has been widely used previously. Wang et al (50) adopted a cell-based ELISA method for the detection of p-CREB (Ser133). In this method, 
an immobilized capture antibody specific for CREB binds to phosphorylated and unphosphorylated proteins. Subsequent to washing the unbound antibodies away, a biotinylated detection antibody that recognizes p-CREB (Ser133) is used to detect only the phosphorylated protein, utilizing a standard streptavidin-HRP format. With this ELISA method, cross-reactivity with unphosphorylated activating transcription factors/CREB family members is minimal, and peptide competition demonstrates that the detection antibody is specific for the Ser133 site of CREB versus other serine phosphorylation sites.

Due to the fact that CREB is a transcription factor, the process of CREB activation and transcriptional mediation is also a focus for research. The traditional detection method is an electrophoretic mobility shift assay (EMSA). However, due to safety concerns regarding the use of radioactive isotopes, radioactive labeling has been replaced by non-radioactive visualization techniques. Xu et al (51) and Fang et al (52) employed an EMSA for the detection of CREB activation. EMSA is a common technique for studying the interaction between DNA and protein or RNA and protein levels. This technology is based on the principle that DNA/protein or RNA/protein complexes have different mobilities in PAGE. When the nuclear transcription factor combines with a specific synthetic DNA or RNA, its migration rate in PAGE will be slower than that of the nuclear transcription factor not bound to DNA. Therefore, activated protein transcription or regulatory factors that interact with DNA or RNA can be detected. The following sequences have been used to study CREB activation: 5'-AGA GATTGCCTGACGTCAGAGAGCTAG-3' and unlabeled 5'-CTAGCTCTCTGACGTCAGGCAATCTCT-3' (53).

The luciferase reporter gene assay (54) involves the transfection of the reporter gene plasmid CREB-Luc into cells. The cells undergo appropriate stimulation and are then lysed, followed by treatment to detect luciferase activity. This method can gauge the expression of a reporter gene easily and effectively. The construction of a reporter gene plasmid is accomplished by cloning the gene transcription regulatory elements upstream of, or at other appropriate locations relative to, the luciferase gene. Cells are transfected with the construct and luciferase activity is detected following treatment or proper stimulation. The influences of different treatments on the targeted regulatory elements, or the differences prior to and subsequent to stimulation, are quantified using the luciferase activity level.

In addition, chromatin immunoprecipitation (ChIP) (3) analysis also can be used to detect the activation of CREB. ChIP is an important method for investigating the interactions between specific proteins or modified forms of proteins and a genomic DNA region (55). ChIP is based on the development of an in vivo analysis method. The basic principle is to selectively enrich a chromosomal fragment (chromatin), which contains a specific antigen. An antibody that can identify a protein or modified protein is used to determine the relative abundance of the antigen at one or more locations in the genome.

Methods to detect PDE. PDE hydrolyzes the intracellular second messengers CAMP and cGMP. PDE terminates the biochemical actions of these second messenger systems by degrading cAMP or cGMP within cells $(56,57)$. A complex PDE gene organization and a great number of PDE splicing variants fine-tune cyclic nucleotide signals and make PDEs conducive to specificity in the signaling pathways (1). Inhibitors of PDE lead to the elevation of cAMP and cGMP levels, which in turn lead to multifarious cellular effects, including airway smooth muscle relaxation, inhibitory effects on cellular inflammation and immune responses (58). The PDE4 inhibitors roflumilast $(59,60)$ and cilomilast (61) have indicated the potential of the development of PDE inhibitors into novel drugs.

Previous studies have used a luminescence-based, high-throughput screening method in place of the enzyme kinetic method for measuring cyclic nucleotide PDE activity. In this method, cNMP (cAMP + cGMP) binds to the inactive PKA holoenzyme, and the regulatory subunits undergo a conformational change, resulting in the release of catalytic subunits. The free catalytic subunits then catalyze the transfer of the terminal phosphate of ATP to a PKA substrate, consuming ATP in the process. The level of remaining ATP is then determined. As PDE hydrolyzes the cNMP, PKA activation is reduced, and increased ATP is available for the luciferase reaction. As a result, luminescence increases. Thus, luminescence is directly proportional to the remaining ATP level, which is directly proportional to the PDE activity (62).

Peter et al (63) used immunoprecipitation and subsequent activity assays to determine total PDE activity. Immunoprecipitation is predominantly used for the qualitative detection of antibodies or antigens. The principle is that the soluble antigens and antibodies form visible sediments in the presence of electrolytes according to their abundance.

PDE has various subtypes, and these subtypes have different functions, the classification of the PDE4 subtype is important in the research and development of novel drugs. PDE4 inhibitors have been reported to specifically prevent the hydrolysis of cAMP (58). There are numerous members of the PDE family, and occasionally, it is necessary to detect one specific member, for example by conducting transfections to detect PDE8A1 (2) or by northern blotting to analyze PDE (A/B/D) (64).

\section{Inhibitors and activators involved in cAMP signaling pathway-associated diseases}

The cAMP signaling pathway and multiple activated factors are involved in regulating numerous physiological processes, including growth, reproduction, differentiation and apoptosis (65). Previous studies have demonstrated that the disruption of the cAMP signaling pathway or the function of any factor within this pathway can contribute to the treatment of numerous human diseases (66-70). For example, by targeting the interruption of the cAMP pathway, a variety of inhibitors of various factors have been identified, and as a result, associated drugs for treating various diseases have been developed.

cAMP-elevating agents. The most widely used inducer of cAMP formation is forskolin, which is an AC activator. Forskolin increases the intracellular concentration of cAMP by activating AC. Numerous studies have demonstrated that forskolin can increase the expression of lipopolysaccharide (LPS)-induced inflammatory factors that are modulated 
via a cAMP-dependent pathway (71) and can enhance the stimulatory function of these factors, including tumor necrosis factor $\alpha$ (72). Forskolin additionally acts as a $\beta$-adrenergic agonist (73), which results in stimulating the transcription of vascular endothelial growth factors (74). Alzheimer's disease has been reported to be associated with an alteration in the activity of AC; therefore, it is suggested that forskolin may be used as a targeted drug to treat Alzheimer's disease (75).

Cholera toxin (CTX) has an effect similar to that of forskolin. Chen et al (23) used forskolin and CTX to increase cAMP levels, and demonstrated that CTX and forskolin were able to increase the expression of iNOS induced by LPS. In addition, dibutyryl-cAMP, a cAMP analog, has been reported to be able to imitate cAMP activation agents $(48,76-78)$.

Inhibitors and activators of PKA. The function of the cAMP signaling pathway is dependent on PKA. H89 is a commonly used PKA inhibitor. H89 is a selective, potent and cell permeable inhibitor of cAMP-dependent PKA. Previous studies have indicated that $\mathrm{H} 89$ blocks LPS-, prostaglandin $\mathrm{E}_{2}$ $\left(\mathrm{PGE}_{2}\right)^{-}$, and phospho-ceramide analogue-1-induced cellular secretion of cyclooxygenase 2 (3), nitric oxide (NO) (7) and additional inflammatory factors such as interleukin $6(26,79)$. Cho et al (80) demonstrated that LPS stimulates the production of inflammatory factors and the amplification of the immune response via the mitogen-activated protein kinase (MAPK) pathway. However, H89 can block the MAPK pathway by inhibiting the CREB-mediated mRNA and protein expression levels of MAPK phosphatase-1 (80), thereby alleviating the inflammatory reaction induced by LPS. Furthermore, $\mathrm{PGE}_{2}$ promotes the proliferation of cholangiocarcinoma cells (CCLP1) through the activation of the cAMP-PKA-CREB pathway, which can be inhibited by H89 (81).

In the process of gastrointestinal inflammation, muscularis macrophages produce NO to induce resident intestinal macrophage dysfunction. $\mathrm{PGE}_{2}$ activates EP2 and EP4 receptors through the activation of the $\mathrm{cAMP} /$ extracellular signal-related kinase pathway, leading to the expression of iNOS. However, EP2 or EP4-mediated iNOS expression can be attenuated by KT-5720 (76). Therefore, inhibitors of PKA can be used in the treatment of gastrointestinal inflammation. Similarly, H89 and KT-5720 can be used to block the production of NO and the expression of iNOS induced by LPS (23).

The only PKA activator commonly used is $\mathrm{Bt}_{2} \mathrm{cAMP}$, also known as dibutyryl-cAMP. Chen et al (23) demonstrated that $\mathrm{Bt}_{2} \mathrm{cAMP}$ directly activates PKA, accelerates LPS-stimulated expression of iNOS in a concentration-dependent manner, and leads to the activation of nuclear factor $(\mathrm{NF})-\kappa \mathrm{B}$ in the nucleus.

Inhibitors of PDE. PDE is the unique intracellular hydrolase for cAMP. The intracellular cAMP concentration is regulated via the stimulation of adenyl and guanyl cyclases in response to extracellular signaling (82). The PDEs are a superfamily of enzymes; there are a minimum of 100 different PDE enzymes, which degrade cyclic nucleotides (1). PDE inhibitors cause an increase in the intracellular concentration of cAMP and have an impact on a variety of cells (58). PDE inhibitors have become a research focus.

PDE inhibitors have the potential to treat incontinence, regulate heart rate disorders, prevent heart failure (62), and antagonize malignant tumors in myeloid and lymphoid tissue and in the prostate $(83,84)$. In addition, PDE isozymes participate in several pathological processes in kidney cells. Therefore, it is suggested that PDE inhibitors can be used for the treatment of nephritis and renal failure (85).

PDE4 inhibitors have been most extensively applied; for example, these inhibitors are used to treat chronic obstructive pulmonary disease (86), inflammation (87), asthma (61), autoimmune diseases (88), and depression (64), in addition to learning and memory disorders (82). The most well known PDE4 inhibitor is rolipram. Rolipram has been demonstrated to significantly increase cAMP levels $(79,89)$, strengthen arginine enzyme activity (90), treat depression (91), ameliorate memory and intelligence (22) and suppress several types of inflammation (92). Rolipram acts by inhibiting PDE4 and reducing CAMP hydrolysis. Due to the fact that rolipram is not highly selective for the PDE4 subtype, this drug has strong side effects, such as inducing vomiting.

Another commonly used inhibitor is 3-isobutyl-1-methylxanthine (93). In addition, a variety of other inhibitors have been developed based on S-adenosylmethionine (SAM). SAM functions as an anti-inflammatory drug and has been demonstrated to act as an effective PDE4B inhibitor for the treatment of chronic inflammatory diseases (94).

Another PDE inhibitor, pentoxifylline, increases intracellular cAMP, acts as an immunosuppressant, has anti-fibrotic activity, and improves hemodynamics. In recent years, pentoxifylline and rolipram have been increasingly used in clinical settings (95). These drugs have been observed to be able to increase bone mass in mice and are thus used in the treatment of osteoporosis. Pentoxifylline and rolipram can block macrophage activation and the production of $\mathrm{NO}$ in vivo and in vitro (5).

Furthermore, pyrazolopyridines (96), as novel PDE4 inhibitors, have the capacity to treat chronic obstructive pulmonary disease, chronic bronchitis and emphysema.

Cilostazol, an inhibitor of PDE3, not only has strong anti-inflammatory effects but also inhibits platelet aggregation and leads to vasodilation (97).

The research and development of PDE5 inhibitors, such as Viagra, Levitra and Cialis, has triggered interest in the function of PDEs in the central nervous system (10). It has been demonstrated that PDE8 serves a decisive role in modulating the concentration of steroids, T-cell adhesion and heart rhythm (2). In addition, Dong et al (98) demonstrated that dipyridamole, an inhibitor of PDE8, strongly inhibited the migration of unstimulated and stimulated splenocytes.

\section{Cross-talk of the cAMP signaling pathway with other pathways}

The presence of several second messengers in addition to cAMP, including $\mathrm{IP}_{3}, \mathrm{cGMP}$ and $\mathrm{Ca}^{2+}$ was mentioned above. Numerous second messenger-mediated signaling pathways have been observed, for example, the NO-cGMP-protein kinase $\mathrm{G}$ pathway (99) and the $\mathrm{IP}_{3}$-diacyl-glycerol-Ca ${ }^{2+}$ double messenger system (the protein kinase C pathway) (100). The physiological processes that occur in vivo and in vitro frequently involve a signaling network, rather than one pathway alone. Various signaling pathways work together to generate 
the corresponding cellular effects, such as the interaction with the NF- $\kappa$ B pathway (101).

Association with the cGMP pathway. A high concentration of one type of nucleotide, cAMP or cGMP, will prevent the generation, metabolism or degradation of the other cyclic nucleotide (102); there is an antagonistic association between the physiological effects. For example, isoproterenol (103) promotes myocardial contraction and increases the concentration of cAMP, while the concentration of cGMP is simultaneously reduced. Liou et al (95) reported that KMUP-1, a xanthine derivative, has osteoclastogenic effects via the cAMP and cGMP pathways with associated inhibitory effects on NF- $\mathrm{BB}, \mathrm{MAPKs}$, and additional factors and pathways. KMUP-1 is able to increase intracellular cAMP and cGMP; therefore, KMUP-1 may potentially be used in the treatment of osteoporosis. From a previous study focussing upon the antidepressant medications fluoxetine and amitriptyline (104), it is known that the cGMP and cAMP signaling pathways are able to function simultaneously. Evidence also indicates that cAMP and cGMP can function in combination.

Association with the NF- $\kappa B$ pathway. The cAMP-PKA and NF- $\mathrm{BB}$ pathways are involved in a variety of physiological functions, such as the anti-inflammatory response (105). The activation of IKB kinase (IKK) is the key step at the beginning of the NF- $\kappa B$ pathway (106). Notably, Chen et al (107) identified that the activation of the PKA pathway can initiate the phosphorylation of IKK $\alpha / \beta$ and NF- $\mathrm{KB}$ p65. SAM acts as an anti-inflammatory drug, the mechanism of which is predominantly attributed to increasing the levels of intracellular cAMP and reducing the activity of NF- $\mathrm{KB}$. Studies have indicated that the cAMP pathway is associated with the transcription of NF- $\mathrm{B}$ (94). Ollivier et al (108) additionally reported that cAMP inhibits NF-kB-mediated transcription in human monocytes and endothelial cells. An additional study demonstrated that SN50, an inhibitor of NF- $\mathrm{kB}$, is able to inhibit the activation of AC induced by LPS (71). AC is the most important enzyme producing cAMP; therefore, AC influences the activation of the cAMP pathway (71). Taken together, this suggested that cAMP is associated with the NF-kB pathway.

Association with the $\mathrm{Ca}^{2+}$ pathway. cAMP and $\mathrm{Ca}^{2+}$ are two important second messengers, which mediate the intracellular effects of cell surface receptors (109). These two second messengers regulate a variety of cellular functions, including protein synthesis, protein phosphorylation, the regulation of enzymatic activity (110) and gene expression. In eukaryotic cells, the cAMP and $\mathrm{Ca}^{2+}$ signaling pathways are cooperative. Landa et al (111) identified that the cAMP and $\mathrm{Ca}^{2+}$ signaling pathways cooperate to regulate insulin secretion in MIN6 $\beta$-cells. Previous studies have demonstrated that cAMP levels can influence the release of $\mathrm{Ca}^{2+}(112)$. Henley et al (113) demonstrated that the $\mathrm{Ca}^{2+}$ signaling pathway is modulated by cAMP. These authors noted that cAMP and $\mathrm{Ca}^{2+}$ regulated the nerve growth cone steering response induced by a variety of channels, and that enhanced $\mathrm{Ca}^{2+}$ signaling was induced by myelin-associated glycoprotein through increasing the activity of the cAMP signaling pathway. Vajanaphanich et al (114) previously suggested that there was cross-talk between the
cAMP and $\mathrm{Ca}^{2+}$ second messenger pathways in secreting cells. This cross-talk may regulate secretion in cells, and cells treated with drugs that simultaneously increase the levels of cAMP and $\mathrm{Ca}^{2+}$ may lead to a synergistic reaction.

\section{Future directions}

The efficiency of the research methods commonly used for elucidating the cAMP signaling pathway must be improved. The high-throughput and high-content screening technologies developed in recent years may be applied to increase the speed of screening for inhibitors and agonists of the cAMP signaling pathway, and may also improve the efficiency of novel drug research and development $(115,116)$. For instance, chIP was shown to markedly shorten the early drug discovery process (115), and recent innovations in flow cytometry have allowed up to 30 -fold faster serial processing of samples (116). The methods of disease treatment described in the present review predominantly focus on blocking or reducing signaling messengers using pathway inhibitors. Conversely, few drugs exert curative effects by increasing the concentration of cAMP. Therefore, further elucidating the role of the cAMP signaling pathway in diseases associated with signal dysfunction and interruption may aid in the development of a therapeutic strategy based on pathway activation.

\section{Acknowledgements}

This review was supported by the National Natural Science Foundation of China (grant no. 81173469) and the National Key Basic Research Program (973 project; grant no. 2014CB542902).

\section{References}

1. Conti M and Beavo J: Biochemistry and physiology of cyclic nucleotide phosphodiesterases: essential components in cyclic nucleotide signaling. Annu Rev Biochem 76: 481-511, 2007.

2. Brown KM, Lee LC, Findlay JE, Day JP and Baillie GS: Cyclic AMP-specific phosphodiesterase, PDE8A1, is activated by protein kinase A-mediated phosphorylation. FEBS Lett 586: 1631-1637, 2012.

3. Diaz-Muñoz MD, Osma-García IC, Fresno M and Iñiguez MA: Involvement of PGE2 and the cAMP signalling pathway in the up-regulation of COX-2 and mPGES-1 expression in LPS-activated macrophages. Biochem J 443: 451-461, 2012.

4. Jhala US, Canettieri G, Screaton RA, Kulkarni RN, Krajewski S, Reed J, Walker J, Lin X, White M and Montminy M: cAMP promotes pancreatic beta-cell survival via CREB-mediated induction of IRS2. Genes Dev 17: 1575-1580, 2003.

5. Beshay E, Croze F and Prud'homme GJ: The phosphodiesterase inhibitors pentoxifylline and rolipram suppress macrophage activation and nitric oxide production in vitro and in vivo. Clin Immunol 98: 272-279, 2001.

6. Park PH, Huang H, McMullen MR, Bryan K and Nagy LE: Activation of cyclic-AMP response element binding protein contributes to adiponectin-stimulated interleukin-10 expression in RAW 264.7 macrophages. J Leukoc Biol 83: 1258-1266, 2008.

7. Chang SY, Kim DB, Ryu GR, Ko SH, Jeong IK, Ahn YB, Jo YH and Kim MJ: Exendin-4 inhibits iNOS expression at the protein level in LPS-stimulated Raw264.7 macrophage by the activation of cAMP/PKA pathway. J Cell Biochem 114: 844-853, 2013.

8. Rosethorne EM, Nahorski SR and Challiss RA: Regulation of cyclic AMP response-element binding-protein (CREB) by Gq/11-protein-coupled receptors in human SH-SY5Y neuroblastoma cells. Biochem Pharmacol 75: 942-955, 2008. 
9. Burdyga A, Conant A, Haynes L, Zhang J, Jalink K, Sutton R, Neoptolemos J, Costello E and Tepikin A: cAMP inhibits migration, ruffling and paxillin accumulation in focal adhesions of pancreatic ductal adenocarcinoma cells: Effects of PKA and EPAC. Biochim Biophys Acta 1833: 2664-2672, 2013.

10. Menniti FS, Faraci WS and Schmidt CJ: Phosphodiesterases in the CNS: Targets for drug development. Nat Rev Drug Discov 5: 660-670, 2006

11. Jang IS, Kang UG, Kim YS, Ahn YM, Park JB and Juhnn YS Isoform-specific changes of adenylate cyclase mRNA expression in rat brains following chronic electroconvulsive shock. Prog Neuropsychopharmacol Biol Psychiatry 25: 1571-1581, 2001.

12. Gloerich M and Bos JL: Epac: Defining a new mechanism for cAMP action. Annu Rev Pharmacol Toxicol 50: 355-375, 2010.

13. Nakajima T, Uchida C, Anderson SF, Parvin JD and Montminy M: Analysis of a cAMP-responsive activator reveals a two-component mechanism for transcriptional induction via signal-dependent factors. Genes Dev 11: 738-747, 1997.

14. Maurice DH, Palmer D, Tilley DG, Dunkerley HA, Netherton SJ, Raymond DR, Elbatarny HS and Jimmo SL: Cyclic nucleotide phosphodiesterase activity, expression and targeting in cells of the cardiovascular system. Mol Pharmacol 64: 533-546, 2003.

15. McLean JH, Smith A, Rogers S, Clarke K, Darby-King A and Harley CW: A phosphodiesterase inhibitor, cilomilast, enhances cAMP activity to restore conditioned odor preference memory after serotonergic depletion in the neonate rat. Neurobiol Learn Mem 92: 63-69, 2009

16. Jackson EK and Dubey RK: Role of the extracellular cAMP-adenosine pathway in renal physiology. Am J Physiol Renal Physiol 281: F597-F612, 2001.

17. Seino $\mathrm{S}$ and Shibasaki T: PKA-dependent and PKA-independent pathways for cAMP-regulated exocytosis. Physiol Rev 85 1303-1342, 2005.

18. Richards JS: New Signaling pathways for hormones and cyclic adenosine 3',5'-monophosphate action in endocrine cells. Mol Endocrinol 15: 209-218, 2001.

19. Guseva D, Wirth A and Ponimaskin E: Cellular mechanisms of the 5-HT7 receptor-mediated signaling. Front Behav Neurosci 8 : 306, 2014.

20. Patterson SL, Abel T, Deuel TA, Martin KC, Rose JC and Kandel ER: Recombinant BDNF rescues deficits in basal synaptic transmission and hippocampal LTP in BDNF knockout mice. Neuron 16: 1137-1145, 1996.

21. Metz R and Ziff E: cAMP stimulates the C/EBP-related transcription factor rNFIL- 6 to trans-locate to the nucleus and induce c-fos transcription. Genes Dev 5: 1754-1766, 1991.

22. Barad M, Bourtchouladze R, Winder DG, Golan H and Kandel E: Rolipram, a type IV-specific phosphodiesterase inhibitor, facilitates the establishment of long-lasting long-term potentiation and improves memory. Proc Natl Acad Sci USA 95: 15020-15025, 1998

23. Chen CC, Chiu KT, Sun YT and Chen WC: Role of the cyclic AMP-protein kinase a pathway in lipopolysaccharide-induced nitric oxide synthase expression in RAW 264.7 macrophages. J Biol Chem 274: 31559-331564, 1999.

24. Moon EY, Lee JH, Lee JW, Song JH and Pyo S: ROS/Epac1-mediated Rap1/NF-kappaB activation is required for the expression of BAFF in Raw264.7 murine macrophages. Cell Signal 23: 1479-1488, 2011

25. DiPilato LM, Cheng $X$ and Zhang J: Fluorescent indicators of cAMP and Epac activation reveal differential dynamics of cAMP signaling within discrete subcellular compartments. Proc Natl Acad Sci USA 101: 16513-16518, 2004.

26. Avni D, Ernst O, Philosoph A and Zor T: Role of CREB in modulation of TNFalpha and IL-10 expression in LPS-stimulated RAW264.7 macrophages. Mol Immunol 47: 1396-1403, 2010

27. Horton JK and Baxendale PM: Mass measurements of cyclic AMP formation by radioimmunoassay, enzyme immunoassay and scintillation proximity assay Methods Mol Biol 41: 91-105, 1995.

28. Costanzo V, Robertson K, Ying CY, Kim E, Avvedimento E, Gottesman M, Grieco D and Gautier J: Reconstitution of an ATM-dependent checkpoint that inhibits chromosomal DNA replication following DNA damage. Mol Cell 6: 649-659, 2000.

29. Costanzo V, Avvedimento EV, Gottesman ME, Gautier J and Grieco D: Protein kinase A is required for chromosomal DNA replication. Curr Biol 9: 903-906, 1999.

30. Smith A, Ward MP and Garrett S: Yeast PKA represses $\mathrm{Msn} 2 \mathrm{p} / \mathrm{Msn} 4 \mathrm{p}$-dependent gene expression to regulate growth, stress response and glycogen accumulation. EMBO J 17: 3556-3564, 1998 .
31. Liu F, Verin AD, Borbiev $\mathrm{T}$ and Garcia JG: Role of cAMP-dependent protein kinase A activity in endothelial cell cytoskeleton rearrangement. Am J Physiol Lung Cell Mol Physiol 280: L1309-L1317, 2001

32. Gerits N, Mikalsen T, Kostenko S, Shiryaev A, Johannessen M and Moens U: Modulation of F-actin rearrangement by the cyclic AMP/cAMP-dependent protein kinase (PKA) pathway is mediated by MAPK-activated protein kinase 5 and requires PKA-induced nuclear export of MK5. J Biol Chem 282: 37232-37243, 2007.

33. Yang W, LV X, Yu S, Guan W, Di D, Wang H and Li J: Effect of cAMP-PKA-CREB signal pathway in the model of alcoholic hepatic fibrosis stellate cells isolated from rats. Anhui Med Pharm J 16: 729-731, 2012.

34. Bruce JI, Shuttleworth TJ, Giovannucci DR and Yule DI Phosphorylation of inositol 1, 4,5-trisphosphate receptors in parotid acinar cells. A mechanism for the synergistic effects of cAMP on Ca2+ signaling. J Biol Chem 277: 1340-1348, 2002.

35. Grønborg M, Kristiansen TZ, Stensballe A, Andersen JS, Ohara O, Mann M, Jensen ON and Pandey A: A mass spectrometry-based proteomic approach for identification of serine/threonine-phosphorylated proteins by enrichment with phospho-specific antibodies: Identification of a novel protein, Frigg, as a protein kinase a substrate. Mol Cell Proteomics 1: $517-527,2002$.

36. Schmitt A and Nebreda AR: Inhibition of Xenopus oocyte meiotic maturation by catalytically inactive protein kinase A. Proc Natl Acad Sci USA 99: 4361-4366, 2002.

37. Lei H, Venkatakrishnan A, Yu S and Kazlauskas A: Protein kinase A-dependent translocation of Hsp90 alpha impairs endothelial nitric-oxide synthase activity in high glucose and diabetes. J Biol Chem 282: 9364-9371, 2007.

38. Goueli BS, Hsiao K and Goueli ASA: A novel and simple method to assay the activity of individual protein kinases in a crude tissue extract. Methods Mol Med 39: 633-644, 2001.

39. Fujikawa H, Kanno T, Nagata T and Nishizaki T: The phosphodiesterase III inhibitor olprinone inhibits hippocampal glutamate release via a cGMP/PKG pathway. Neurosci Lett 448: 208-211, 2008.

40. Kanno T, Yamamoto H, Yaguchi T, Hi R, Mukasa T, Fujikawa H, Nagata T, Yamamoto S, Tanaka A and Nishizaki T: The linoleic acid derivative DCP-LA selectively activates PKC-epsilon, possibly binding to the phosphatidylserine binding site. J Lipid Res 47: 1146-1156, 2006.

41. Brindlet P, Nakajima T and Montminy M: Multiple protein kinase A-regulated events are required for transcriptional induction by cAMP (cAMP response element-binding protein). Proc Natl Acad Sci USA 92: 10521-10525, 1995.

42. Shih HM, Goldman PS, DeMaggio AJ, Hollenberg SM, Goodman RH and Hoekstra MF: A positive genetic selection for disrupting protein-protein interactions: Identification of CREB mutations that prevent association with the coactivator CBP. Proc Natl Acad Sci USA 93: 13896-13901, 1996.

43. Ferreri K, Gillt G and Montminy M: The cAMP-regulated transcription factor CREB interacts with a component of the TFIID complex (glutamine-rich activator/TATA binding protein-associated factor dTAF11O). Proc Natl Acad Sci USA 91: 1210-1213, 1994.

44. Ginty DD: Calcium regulation of gene expression: Isn't that spatial? Neuron 18: 183-186, 1997.

45. Parker D, Ferreri K, Nakajima T, LaMorte VJ, Evans R, Koerber SC, Hoeger C and Montminy MR: Phosphorylation of CREB at Ser-133 induces complex formation with CREB-binding protein via a direct mechanism. Mol Cell Biol 16: 694-703, 1996

46. Silva AJ, Kogan JH, Frankland PW and Kida S: CREB and memory. Neurosci 21: 127-148, 1998.

47. Riccio A, Alvania RS, Lonze BE, Ramanan N, Kim T, Huang Y, Dawson TM, Snyder SH and Ginty DD: A nitric oxide signaling pathway controls CREB-mediated gene expression in neurons. Mol Cell 21: 283-294, 2006.

48. Moon EY, Lee YS, Choi WS and Lee MH: Toll-like receptor 4-mediated cAMP production up-regulates B-cell activating factor expression in Raw264.7 macrophages. Exp Cell Res 317: 2447-2455, 2011

49. Deng H, Zhang N, Wang Y, Chen J, Shen J, Wang Z, Xu R, Zhang J, Song D and Li D: S632A3, a new glutarimide antibiotic, suppresses lipopolysaccharide-induced pro-inflammatory responses via inhibiting the activation of glycogen synthase kinase 33. Exp Cell Res 318: 2592-2603, 2012. 
50. Wang QS, Tian JS, Cui YL and Gao S: Genipin is active via modulating monoaminergic transmission and levels of brain-derived neurotrophic factor (BDNF) in rat model of depression. Neuroscience 275: 365-373, 2014

51. Xu G, Tu W and Qin AS: The relationship between deiodinase activity and inflammatory responses under the stimulation of uremic toxins. J Transl Med 12: 239, 2014.

52. Fang JQ, Jun JF, Liang Y and Du JY: Electroacupuncture mediates extracellular signalregulated kinase $1 / 2$ pathways in the spinal cord of rats with inflammatory pain. BMC Complement Altern Med 14: 285, 2014

53. Guan CX, Cui YR, Sun GY, Yu F, Tang CY, Li YC, Liu HJ and Fang X: Role of CREB in vasoactive intestinal peptide-mediated wound healing in human bronchial epithelial cells. Regul Pept 153: 64-69, 2009.

54. Yang Y, Yu T, Lee YG, Yang WS, Oh J, Jeong D, Lee S, Kim TW, Park YC, Sung GH and Cho JY: Methanol extract of Hopea odorata suppresses inflammatory responses via the direct inhibition of multiple kinases. J Ethnopharmacol 145: 598-607, 2013.

55. Carey MF, Peterson CL and Smale ST: Chromatin immunoprecipitation (ChIP). Cold Spring Harb Protoc 2009: pdb prot5279, 2009.

56. Andreeva SG, Dikkes P, Epstein PM and Rosenberg PA: Expression of cGMP-Specific Phosphodiesterase 9A mRNA in the rat brain. J Neurosci 21: 9068-9076, 2001.

57. Lugnier C: Cyclic nucleotide phosphodiesterase (PDE) superfamily: A new target for the development of specific therapeutic agents. Pharmacol Ther 109: 366-398, 2006.

58. Nanda K, Chatterjee M, Arya R, Mukherjee S, Saini KS Dastidar S and Ray A: Optimization and validation of a reporter gene assay for screening of phosphodiesterase inhibitors in a high throughput system. Biotechnol J 3: 1276-1279, 2008.

59. Page CP and Spina D: Selective PDE inhibitors as novel treatments for respiratory diseases. Curr Opin Pharmacol 12: 275-286, 2012

60. Pinner NA, Hamilton LA and Hughes A: Roflumilast: A phosphodiesterase-4 inhibitor for the treatment of severe chronic obstructive pulmonary disease. Clin Ther 34: 56-66, 2012.

61. Spina D: PDE4 inhibitors: Current status. Br J Pharmacol 155 308-315, 2008

62. Lehnart SE, Wehrens XH, Reiken S, Warrier S, Belevych AE, Harvey RD, Richter W, Jin SL, Conti M and Marks AR: Phosphodiesterase 4D deficiency in the ryanodine-receptor complex promotes heart failure and arrhythmias. Cell 123: 25-35, 2005

63. Peter D, Jin SL, Conti M, Hatzelmann A and Zitt C: Differential expression and function of phosphodiesterase 4 (PDE4) subtypes in human primary CD4+ T cells: Predominant role of PDE4D. J Immunol 178: 4820-4831, 2007.

64. Takahashi M, Terwilliger R, Lane C, Mezes PS, Conti M and Duman RS: Chronic antidepressant administration increases the expression of cAMP-specific phosphodiesterase 4A and 4B isoforms. J Neurosci 19: 610-618, 1999.

65. Jin L, Hill KK, Filak H, Mogan J, Knowles H, Zhang B, Perraud AL, Cambier JC and Lenz LL: MPYS is required for IFN response factor 3 activation and type I IFN production in the response of cultured phagocytes to bacterial second messengers cyclic-di-AMP and cyclic-di-GMP. J Immunol 187: 2595-2601, 2011.

66. Liu X, Guo H, Sayed MD, Lu Y, Yang T, Zhou D, Chen Z, Wang $\mathrm{H}$, Wang $\mathrm{C}$ and $\mathrm{Xu} \mathrm{J}$ : cAMP/PKA/CREB/GLT1 signaling involved in the antidepressant-like effects of phosphodiesterase 4D inhibitor (GEBR-7b) in rats. Neuropsychiatr Dis Treat 12 219-227, 2016

67. Kono Y and Hülsmann S: Presynaptic facilitation of glycinergic mIPSC is reduced in mice lacking $\alpha 3$ glycine receptor subunits. Neuroscience 320: 1-7, 2016.

68. Ramakrishnan SK, Zhang H, Takahashi S, Centofanti B, Periyasamy S, Weisz K, Chen Z, Uhler MD, Rui L, Gonzalez FJ and Shah YM: HIF $2 \alpha$ Is an Essential Molecular Brake for Postprandial Hepatic Glucagon Response Independent of Insulin Signaling. Cell Metab: Feb 3, 2016 (Epub ahead of print).

69. Pal S, Khan K, China SP, Mittal M, Shrivastava R, Taneja I, Hossain Z, Mandalapu D, Gayen JR, et al: Theophylline, a methylxanthine drug induces osteopenia and alters calciotropic hormones, and prophylactic vitamin D treatment protects against these changes in rats. Toxicol Appl Pharmacol: Feb 3, 2016 (Epub ahead of print)
70. Bobin P, Varin A, Lefebvre F, Fischmeister R, Vandecasteele G and Leroy J: Calmodulin kinase II inhibition limits the pro-arrhythmic Ca2+ waves induced by cAMP-phosphodiesterase inhibitors. Cardiovasc Res: Feb 4, 2016 (Epub ahead of print).

71. Osawa Y, Lee HT, Hirshman CA, Xu D and Emala CW: Lipopolysaccharide-induced sensitization of adenylyl cyclase activity in murine macrophages. Am J Physiol Cell Physiol 290: C143-C151, 2006.

72. Kobayashi Y, Mizoguchi T, Take I, Kurihara S, Udagawa N and Takahashi N: Prostaglandin E2 enhances osteoclastic differentiation of precursor cells through protein kinase A-dependent phosphorylation of TAK1. J Biol Chem 280: 11395-11403, 2005.

73. Malbon CC and Graziano MP: Adenosine deaminase normalizes cyclic AMP responses of hypothyroid rat fat cells to forskolin, but not beta-adrenergic agonists. FEBS Lett 155: 35-38, 1983.

74. Jeon SH, Chae BC, Kim HA, Seo GY, Seo DW, Chun GT, Yie SW, Eom SH and Kim PH: The PKA/CREB Pathway is closely involved in VEGF expression in mouse macrophages. Mol Cells 23: 23-29, 2007.

75. Burgos-Ramos E, Hervás-Aguilar A, Puebla-Jiménez L, Boyano-Adánez MC and Arilla-Ferreiro E: Chronic but not acute intracerebroventricular administration of amyloid beta-peptide (25-35) decreases somatostatin content, adenylate cyclase activity, somatostatin-induced inhibition of adenylate cyclase activity and adenylate cyclase I levels in the rat hippocampus. J Neurosci Res 85: 433-442, 2007.

76. Tajima T, Murata T, Aritake K, Urade Y, Michishita M, Matsuoka T, Narumiya S, Ozaki H and Hori M: EP2 and EP4 receptors on muscularis resident macrophages mediate LPS-induced intestinal dysmotility via iNOS upregulation through cAMP/ERK signals. Am J Physiol Gastrointest Liver Physiol 302: G524-G534, 2012.

77. Okado-Matsumoto A, Matsumoto A, Fujii J and Taniguchi N: Effect of cAMP on inducible nitric oxide synthase gene expression: Its dual and cell-specific functions. Antioxid Redox Signal 2: 631-642, 2000

78. Mukhopadhyay S, Das S, Williams EA, Moore D, Jones JD, Zahm DS, Ndengele MM, Lechner AJ and Howlett AC: Lipopolysaccharide and cyclic AMP regulation of $\mathrm{CB}(2)$ cannabinoid receptor levels in rat brain and mouse RAW 264.7 macrophages. J Neuroimmunol 181: 82-92, 2006.

79. Goldsmith M, Avni D, Ernst O, Glucksam Y, Levy-Rimler G Meijler MM and Zor T: Synergistic IL-10 induction by LPS and the ceramide-1-phosphate analog PCERA-1 is mediated by the cAMP and p38 MAP kinase pathways. Mol Immunol 46: 1979-1987, 2009

80. Cho IJ, Woo NR, Shin IC and Kim SG: H89, an inhibitor of PKA and MSK, inhibits cyclic-AMP response element binding protein-mediated MAPK phosphatase-1 induction by lipopolysaccharide. Inflamm Res 58: 863-872, 2009.

81. Ma J, Chen M, Xia SK, Shu W, Guo Y, Wang YH, Xu Y, Bai XM, Zhang L, Zhang H, et al: Prostaglandin E2 promotes liver cancer cell growth by the upregulation of FUSE-binding protein 1 expression. Int J Oncol 42: 1093-1104, 2013.

82. Kotomi F, Kotera J, Michibata H, Yuasa K, Takebayashi S, Okumura $\mathrm{K}$ and Omori $\mathrm{K}$ : Cloning and Characterization of a novel human phosphodiesterase that hydrolyzes both cAMP and cGMP (PDE10A). J Biol Chem 274: 18438-18445, 1999.

83. Wheeler MA, Ayyagari RR, Wheeler GL and Weiss RM: Regulation of cyclic nucleotides in the urinary tract. J Smooth Muscle Res 41: 1-21, 2005.

84. Lerner A and Epstein PM: Cyclic nucleotide phosphodiesterases as targets for treatment of haematological malignancies. Biochem J 393: 21-41, 2006.

85. Dousa TP: Cyclic-3',5'-nucleotide phosphodiesterase isozymes in cell biology and pathophysiology of the kidney. Kidney Int 55: 29-62, 1999

86. Lipworth BJ: Phosphodiesterase-4 inhibitors for asthma and chronic obstructive pulmonary disease. Lancet 365: 167-175, 2005.

87. Dastidar SG, Rajagopal D and Ray A: Therapeutic benefit of PDE4 inhibitors in inflammatory diseases. Curr Opin Investig Drugs 8: 364-372, 2007

88. Bielekova B, Lincoln A, McFarland H and Martin R: Therapeutic potential of phosphodiesterase- 4 and-3 inhibitors in Th1-mediated autoimmune diseases. J Immunol 164: 1117-1124, 2000. 
89. Avni D, Philosoph A, Meijler MM and Zor T: The ceramide-1-phosphate analogue PCERA-1 modulates tumour necrosis factor-alpha and interleukin-10 production in macrophages via the cAMP-PKA-CREB pathway in a GTP-dependent manner. Immunology 129: 375-385, 2010.

90. Sosroseno W, Musa M, Ravichandran M, Fikri Ibrahim M, Bird PS and Seymour GJ: The role of cyclic-AMP on arginase activity by a murine macrophage cell line (RAW264.7) stimulated with lipopolysaccharide from Actinobacillus actinomycetemcomitans. Oral Microbiol Immunol 21: 347-352, 2006.

91.Navakkode S, Sajikumar S and Frey JU: Mitogen-activated protein kinase-mediated reinforcement of hippocampal early long-term depression by the type IV-specific phosphodiesterase inhibitor rolipram and its effect on synaptic tagging. J Neurosci 25: 10664-10670, 2005.

92. Chi ZL, Hayasaka S, Zhang XY, Hayasaka Y and Cui HS: Effects of rolipram, a selective inhibitor of type 4 phosphodiesterase, on lipopolysaccharide-induced uveitis in rats. Invest Ophthalmol Vis Sci 45: 2497-2502, 2004.

93. Yoshimura K, Hiramatsu Y and Murakami M: Cyclic AMP potentiates substance P-induced amylase secretion by augmenting the effect of calcium in the rat parotid acinar cells. Biochim Biophys Acta 1402: 171-187, 1998.

94. Gobejishvili L, Avila DV, Barker DF, Ghare S, Henderson D, Brock GN, Kirpich IA, Joshi-Barve S, Mokshagundam SP, McClain CJ and Barve S: S-adenosylmethionine decreases lipopolysaccharide-induced phosphodiesterase 4B2 and attenuates tumor necrosis factor expression via cAMP/protein kinase $\mathrm{A}$ pathway. J Pharmacol Exp Ther 337: 433-443, 2011.

95.Liou SF, Hsu JH, Lin IL, Ho ML, Hsu PC, Chen LW, Chen IJ and Yeh JL: KMUP-1 suppresses RANKL-induced osteoclastogenesis and prevents ovariectomy-induced bone loss: Roles of MAPKs, Akt, NF-kB and calcium/calcineurin/NFATc1 pathways. PLoS One 8: e69468, 2013.

96. Hamblin JN, Angell TD, Ballantine SP, Cook CM, Cooper AW, Dawson J, Delves CJ, Jones PS, Lindvall M, Lucas FS, et al: Pyrazolopyridines as a novel structural class of potent and selective PDE4 inhibitors. Bioorg Med Chem Lett 18: 4237-4241, 2008.

97.Park WS, Jung WK, Lee DY, Moon C, Yea SS, Park SG, Seo SK, Park C, Choi YH, Kim GY, et al: Cilostazol protects mice against endotoxin shock and attenuates LPS-induced cytokine expression in RAW 264.7 macrophages via MAPK inhibition and NF-kappaB inactivation: Not involved in cAMP mechanisms. Int Immunopharmacol 10: 1077-1085, 2010.

98.Dong H, Osmanova V, Epstein PM and Brocke S Phosphodiesterase 8 (PDE8) regulates chemotaxis of activated lymphocytes. Biochem Biophys Res Commun 345: 713-719, 2006.

99. Wunder F, Stasch JP, Hütter J, Alonso-Alija C, Hüser J and Lohrmann E: A cell-based cGMP assay useful for ultra-high-throughput screening and identification of modulators of the nitric oxide/cGMP pathway. Anal Biochem 339: 104-112, 2005.

100.Lallemend F, Lefebvre PP, Hans G, Rigo JM, Van de Water TR Moonen $G$ and Malgrange B: Substance P protects spiral ganglion neurons from apoptosis via PKC-Ca ${ }^{2}+$-MAPK/ERK pathways. J Neurochem 87: 508-521, 2003.

101. Gilmore TD: Introduction to NF-kappaB: Players, pathways, perspectives. Oncogene 25: 6680-6684, 2006.
102. Denninger JW and Marletta MA: Guanylate cyclase and the. NO/cGMP signaling pathway. Biochim Biophys Acta 1411: 334-350, 1999 .

103. Edgar VA, Cremaschi GA, Sterin-Borda L and Genaro AM: Altered expression of autonomic neurotransmitter receptors and proliferative responses in lymphocytes from a chronic mild stress model of depression: Effects of fluoxetine. Brain Behav Immun 16: 333-350, 2002

104. Reierson GW, Mastronardi CA, Licinio J and Wong ML: Repeated antidepressant therapy increases cyclic GMP signaling in rat hippocampus. Neurosci Lett 466: 149-153, 2009.

105. Lee AK, Sung SH, Kim YC and Kim SG: Inhibition of lipopolysaccharide-inducible nitric oxide synthase, TNF-alpha and COX-2 expression by sauchinone effects on I-kappaBalpha phosphorylation, C/EBP and AP-1 activation. Br J Pharmacol 139: $11-20,2003$.

106.Zandi E, Rothwarf DM, Delhase M, Hayakawa M and Karin M: The IkB kinase complex (IKK) contains two kinase subunits, IKKalpha and IKKbeta, Necessary for IkappaB Phosphorylation and NF-kappaB activation. Cell 91: 243-252, 1997.

107. Chen BC, Liao CC, Hsu MJ, Liao YT, Lin CC, Sheu JR and Lin CH: Peptidoglycan-induced IL-6 production in RAW 264.7 macrophages is mediated by cyclooxygenase-2, PGE2/PGE4 receptors, protein kinase A, I kappa B Kinase and NF-kappa B. J Immunol 177: 681-693, 2006.

108. Ollivier V, Parry GC, Cobb RR, de Prost D and Mackman N: Elevated cyclic AMP inhibits NF-kappaB-mediated transcription in human monocytic cells and endothelial cells. J Biol Chem 271: 20828-20835, 1996.

109. Hofer AM and Lefkimmiatis K: Extracellular calcium and cAMP: Second messengers as 'third messengers'? Physiology (Bethesda) 22: 320-327, 2007.

110. Bhalla US and Iyengar R: Emergent properties of networks of biological signaling pathways. Science 283: 381-387, 1999.

111. Landa LR Jr, Harbeck M, Kaihara K, Chepurny O, Kitiphongspattana K, Graf O, Nikolaev VO, Lohse MJ, Holz GG and Roe MW: Interplay of $\mathrm{Ca} 2+$ and cAMP signaling in the insulin-secreting MIN6 beta-cell line. J Biol Chem 280: 31294-31302, 2005

112. Moore TM, Chetham PM, Kelly JJ and Stevens T: Signal transduction and regulation of lung endothelial cell permeability. Interaction between calcium and cAMP. Am J Physiol 275: L203-L222, 1998.

113. Henley JR, Huang KH, Wang D and Poo MM: Calcium mediates bidirectional growth cone turning induced by myelin-associated glycoprotein. Neuron 44: 909-916, 2004.

114. Vajanaphanich M, Schultz C, Tsien RY, Traynor-Kaplan AE, Pandol SJ and Barrett KE: Cross-talk between calcium and cAMP-dependent intracellular signaling pathways. Implications for synergistic secretion in T84 colonic epithelial cells and rat pancreatic acinar cells. J Clin Invest 96: 386-393, 1995.

115. Kapur R, Giuliano KA., Campana M, Adams T, Olson K, Jung D, Mrksich M, Chandrasekaran V and Taylor DL: Streamlining the drug discovery process by integrating miniaturization, high throughput screening, high content screening, and automation on the CellChip ${ }^{\mathrm{TM}}$ system. Biomed Microdevices 2: 99-109, 1999.

116. Edwards BS, Oprea T, Prossnitz ER and Sklar LA: Flow cytometry for high-throughput, high-content screening. Curr Opin Chem Biol 8: 392-398, 2004. 